
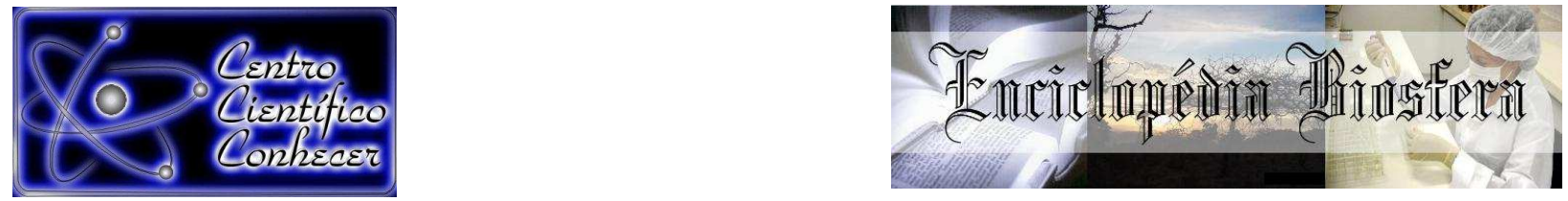

\title{
QUIMIOTERAPIA, HORMONIOTERAPIA E NOVAS ALTERNATIVAS DE TRATAMENTO DO ADENOCARCINOMA MAMÁRIO
}

Gabriela Hadler Gabriel ${ }^{1}$, Leandro Lopes Nepomuceno ${ }^{2}$, Vanessa de Sousa Cruz Pimenta $^{3}$, Eugênio Gonçalves de Araújo ${ }^{4}$

1 Mestranda do Programa de Pós-Graduação em Ciência Animal da Escola de

Veterinária e Zootecnia da Universidade Federal de Goiás

(gabriela.hadler@hotmail.com)

Goiás-Brasil

2 Doutorando do Programa de Pós-Graduação em Ciência Animal da Escola de

Veterinária e Zootecnia da Universidade Federal de Goiás

3 Pós doutoranda, Laboratório Multiusuário de Cultivo Celular da Universidade

Federal de Goiás

4 Professor Doutor do Setor de Patologia Veterinária da Universidade Federal de Goiás

Recebido em: 02/10/2017 - Aprovado em: 21/11/2017 - Publicado em: 05/12/2017 DOI: 10.18677/EnciBio_2017B56

\section{RESUMO}

O câncer de mama é um importante problema de saúde pública, com altas taxas de mortalidade relacionadas ao diagnóstico tardio. Vários são os fatores de risco que levam ao aparecimento do tumor, e as mulheres são mais frequentemente acometidas, principalmente em idade superior aos 50 anos. $O$ tratamento de escolha é a remoção cirúrgica do tumor, radioterapia, quimioterapia e hormonioterapia, com objetivo de promover morte das células tumorais. Os tratamentos quimioterápico e hormonioterápico estão associados a uma alta incidência de efeitos adversos, o que compromete o tratamento, por reduzir a qualidade de vida da paciente. Essa incidência de reações adversas justifica a constante busca por novas formas de tratamento, que tenham ação mais seletiva, melhorando a expectativa de vida dos pacientes e as perspectivas de tratamento.

PALAVRAS-CHAVE: câncer de mama, fitoterápicos, quimioterapia.

\section{CHEMOTHERAPY, HORMONIOTHERAPY AND NEW ALTERNATIVES FOR TREATMENT OF MAMMARY ADENOCARCINOMA}

\begin{abstract}
Breast cancer is an important public health problem, with high mortality rates related to late diagnosis. Several are the risk factors that lead to the appearance of the tumor, and women are most frequently affected, especially in the age of 50 years. The treatment of choice is the surgical removal of the tumor, radiotherapy, chemotherapy and hormone therapy, with the goal of promoting tumor cell death. The chemotherapeutic and hormone therapy treatments are associated with a high
\end{abstract}


incidence of adverse effects, which compromises the treatment, by reducing the quality of life of the patient. This incidence of adverse reactions justifies the constant search for new forms of treatment that have a more selective action, improving patients' life expectancy and treatment prospects.

KEYWORDS: breast cancer, chemotherapy, herbal medicines.

\section{INTRODUÇÃO}

O câncer de mama é o segundo tipo de neoplasia mais frequente no mundo e o mais frequente entre as mulheres, sendo considerado um tumor de bom prognóstico. Porém, o diagnóstico em estágios tardios e avançados justifica o fato de a doença ainda ser responsável por altas taxas de mortalidade no Brasil e no mundo (SILVA et al., 2011).

O carcinoma mamário é classificado como um grupo de tumores epiteliais malignos que se caracterizam por invadir tecidos adjacentes e pela alta capacidade de formação de metástases à distância. São neoplasias heterogêneas que exibem vários subtipos patológicos e diferentes aspectos no que se refere à histologia tumoral, além de apresentações variadas quanto aos aspectos clínicos e respostas ao tratamento (CINEGAGLIA et al., 2013).

Os fatores de risco que levam ao aparecimento do câncer de mama são inúmeros e incluem a menarca precoce, nuliparidade, menopausa tardia, primiparidade em idade avançada, não amamentação, história de doença benigna ou maligna nas mamas, histórico familiar de câncer mamário em um ou mais parentes de primeiro grau. Há também outros fatores que são comuns para outros tipos de câncer, como a obesidade, consumo de álcool, dieta rica em gorduras animais e exposição a altas doses de radiação (VIEIRA et al., 2008). Além disso, as taxas de incidência são maiores nas mulheres com idade superior a 50 anos (SAWADA et al., 2009).

Existem vários tratamentos disponíveis para o câncer de mama, entre eles o tratamento cirúrgico, radioterápico e sistêmico, o qual pode ser dividido em diferentes tipos, como a quimioterapia e hormonioterapia. A cirurgia de escolha é a mastectomia, que tem como objetivo o controle local da doença e sua disseminação por via venosa e linfática. Já a radioterapia se baseia no uso da radiação para eliminação das células tumorais, porém, seu emprego depende do tipo e estágio do tumor (ZHANG et al., 2013).

A hormônioterapia, por sua vez, baseia-se na utilização de agentes como o tamoxifeno, que apresenta efeito antagônico ao estrogênio. No entanto, inúmeros são os efeitos colaterais relatados em pacientes que fizeram seu uso, incluindo alterações visuais, náuseas e vômitos, constipação, alterações menstruais, endométricas e hepáticas, boca e pele secas, dor, leucorreia e diarreia (OKINO SAWADA et al., 2009).

O principal objetivo do uso de drogas quimioterápicas é a morte das células tumorais. As duas classes de medicamentos mais utilizados para o tratamento do câncer de mama atuam por meio do desencadeamento de apoptose nas células tumorais. Os taxanos reprimem e inibem o crescimento celular, diferenciação e proliferação em várias linhagens de câncer, sendo conhecidos como inibidores de mitose. Já as antraciclinas são antibióticos antitumorais que atuam na inibição da enzima topoisomerase II, impedindo a replicação do DNA tumoral e promovendo morte celular (ZHANG et al., 2013). 
A quimioterapia tem sido uma das principais formas de tratamento do câncer de mama, e pode ser feita por meio da utilização de agentes químicos, isolados ou combinados, que atuam de forma sistêmica no processo de crescimento e divisão das células ativas, impedindo a progressão da doença. O grande problema encontra-se no fato de que os agentes também afetam as células não-neoplásicas do paciente, o que explica o surgimento dos efeitos colaterais (CINEGAGLIA et al., 2013).

De forma geral, os quimioterápicos são bem tolerados, e é possível controlar os efeitos colaterais por meio da manutenção das dosagens dos tratamentos e uso de fármacos auxiliares, como os antieméticos. Os principais efeitos tóxicos incluem a supressão da medula óssea e da imunidade, náuseas e vômitos, alopecia, nefrotoxicidade, cardiotoxicidade, toxicidade pulmonar, neurotoxicidade, lesão gonadal e, em alguns casos, esterilidade. Já as consequências clínicas do tratamento quimioterápico incluem lesão esofágica, fraturas, má-nutrição, desequilíbrios hidroeletrolítico e ácido-básico e redução da qualidade de vida do paciente, que muitas vezes abandona o tratamento ou opta por períodos de pausa, comprometendo a eficácia da terapia (SOUZA; FELFILI, 2006).

A incidência de reações indesejadas justifica a busca por novos agentes antineoplásicos. Também é importante salientar que, embora a mortalidade tenha diminuído, não houve melhora significativa nas taxas de cura, o que torna necessário o desenvolvimento de pesquisas sobre novas drogas e tratamentos alternativos que tenham uma ação seletiva e sejam capazes de melhorar os resultados, a expectativa de vida dos pacientes e diminuir os efeitos adversos (CINEGAGLIA et al., 2013; DE CASTRO et al., 2013).

Diante disso, essa revisão de literatura teve por objetivo reunir os principais agentes antineoplásicos utilizados no tratamento de pacientes com adenocarcinoma mamário, bem como trazer informações sobre novas drogas e terapias alternativas.

\section{QUIMIOTERAPIA}

A quimioterapia consiste no tratamento com fármacos que podem ser administrados por via intravenosa ou via oral. É geralmente indicada no tratamento adjuvante, após a mastectomia, para completa destruição das células neoplásicas e redução da ocorrência de recidivas (RUBOVSZKY; HORVÁTH, 2017), aumentando a sobrevida dos pacientes. Todavia, pode ser realizada antes da cirurgia, numa tentativa de reduzir do tumor e a extensão da cirurgia, nesse caso, sendo chamada de quimioterapia neoadjuvante (CINTRA et al., 2008).

A duração do tratamento é determinada de acordo com a incidência de efeitos adversos e da resposta tumoral, variando de três a seis meses. Os fármacos citostáticos mais ativos no tratamento do câncer de mama são as antraciclinas, como a epirrubicina e doxorrubicina, e os taxanos, como o paclitaxel e docetaxel (RUBOVSZKY ; HORVÁTH, 2017).

\section{ANTRACICLINAS}

Dentro desse grupo de fármacos, destacam-se a doxorrubicina e seu análogo estrutural, a epirrubicina, esta segunda responsável por causar menores efeitos cardiotóxicos (MONTEIRO et al., 2013). As antraciclinas são antibióticos antitumorais que atuam por meio da alteração da fluidez e transporte de íons na membrana celular, formação de radicais livres e ruptura dos filamentos de DNA, por ENCICLOPÉDIA BIOSFERA, Centro Científico Conhecer - Goiânia, v. 14 n.26; p. 585 2017 
meio da inibição da enzima topoisomerase II (CARVALHO et al., 2015). Apesar da utilização da antraciclina promover um aumento de cerca de $4 \%$ na sobrevida dos pacientes, o uso dessa classe de medicamentos está associado à ocorrência de cardiotoxicidade e trombose (MONTEIRO et al., 2013).

Outro grande problema na utilização das antraciclinas é a ocorrência de resistência quimioterápica, prejudicando o sucesso do tratamento do câncer de mama. Para minimizar essa resistência, um teste em células da linhagem no qual foi realizada uma associação entre a metformina e a doxorrubicina, demonstrou que 0 uso da metformina possibilita um aumento na sensibilidade à doxorrubicina ao potencializar sua ação e minimizar as chances de resistência (SHAFIEI-IRANNEJAD et al., 2017).

A utilização de vitamina D3 combinada à doxorrubicina também é capaz de aumentar a eficácia deste quimioterápico. Estudos em células MCF-7 mostraram que a utilização de vitamina D carregada com lipídeos nanoestruturados em administração concomitante a doxorrubicina elevou a eficácia do quimioterápico, agindo no aumento da ocorrência de apoptose das células tumorais (SABZICHI et al., 2017).

Do mesmo modo, a utilização da anfotericina B é capaz de potencializar a atividade antineoplásica da doxorrubicina em células da linhagem MCF-7. Como consequência, ocorre morte celular por apoptose em porcentagem maior do que nas células tratadas apenas com a doxorrubicina (TAVANGAR et al., 2017).

\section{TAXANOS}

No tratamento do câncer de mama, os taxanos mais utilizados são o paclitaxel e o docetaxel. O primeiro foi inicialmente obtido a partir de uma árvore conífera denominada teixo (Taxus spp gênero Taxaceae), enquanto o último, que é o análogo semi-sintético, é produzido a partir do Taxus baccata, o teixo europeu (MONTEIRO et al., 2013).

Podem ser utilizados de forma adjuvante, mas sua maior utilização ocorre em associação as antraciclinas na quimioterapia neoadjuvante, garantindo uma maior eficácia do tratamento (RUBOVSZKY; HORVÁTH, 2017). A associação de antraciclinas e taxanos resulta num potente protocolo de tratamento para o câncer de mama, pois o uso das duas drogas combinadas é capaz de promover um aumento de 3 a 5\% na sobrevida dos pacientes, além de proporcionar redução na ocorrência de recidivas. Assim como no caso das antraciclinas, o uso dos taxanos resulta na ocorrência de efeitos adversos; os mais frequentes são a mielossupressão, náuseas, vômitos e outras alterações gastrointestinais, neurotoxicidade, cardiotoxicidade, reações alérgicas e alterações cutâneas (SOUCHEK et al., 2017).

Os taxanos agem por meio da quebra de microtúbulos que são formados no início da divisão celular, causando inibição do processo de mitose e induzindo apoptoses programadas durante as fases $\mathrm{G} 2$ e $\mathrm{M}$ do ciclo celular. Com isso, as células neoplásicas ficam impossibilitadas de se dividirem, freando o crescimento tumoral e causando morte celular (MONTEIRO et al., 2013).

Os protocolos baseados na utilização dos fármacos taxanos de forma prévia à utilização das antraciclinas mostraram bons resultados, principalmente durante o tratamento neoadjuvante (SOUCHEK et al., 2017). Ademais os benefícios farmacológicos das antraciclinas no tratamento adjuvante dos pacientes são 
maximizados quando utilizadas em associação aos taxanos (CURIGLIANO; CRISCITIELLO, 2017).

A resistência aos taxanos também é um problema no tratamento dos pacientes com câncer de mama. A silibinina, um componente ativo da silimarina obtida da Silybum marianum, ao apresentar efeito sinérgico em combinação com o paclitaxel, aumentou a eficiência do tratamento das células da linhagem MCF-7 (MOLAVI et al., 2017).

\section{PROTOCOLO CMF}

Este protocolo é o resultado da associação entre a ciclofosfamida, metotrexato e 5-fluorouracil. Embora apresente resultados menos satisfatórios em comparação ao uso dos taxanos e antraciclinas, continua sendo uma opção muito utilizada devido ao seu baixo custo (JAIN et al., 2017).

A ciclofosfamida, fármaco da classe dos agentes alquilantes que atua destruindo as células tumorais, compõe o grupo de agentes não específicos do ciclocelular que agem na inibição da replicação celular (ALMEIDA et al., 2005). Esses são geralmente usados em combinações com outros fármacos, fato este que possibilita uma maior atividade nas células neoplásicas em comparação aos protocolos que utilizam o fármaco de forma isolada (JAIN et al., 2017).

O metotrexato, por sua vez, age privando a célula de folatos, os quais são essenciais na formação do DNA. Juntamente com o 5-fluorouracil, é considerado um fármaco antimetabólito, pois atua na síntese de ácidos nucléicos e inibição de reações enzimáticas (JOSHI et al., 2017). São quimioterápicos ciclo-celular específicos e agem na fase $S$ do ciclo por ação metabólica, ao promover bloqueio na síntese de DNA (WU et al., 1899).

Os antimetabólitos atuam na fase $S$ do ciclo celular e podem ser agrupados em subclasses, de acordo com seu mecanismo de ação. Existem os análogos do ácido fólico, como o metotrexato, os antagonistas das pirimidinas, como a citarabina e floxuridina, e os análogos das purinas, como a mercaptopurina e pentostatina (DE SANCTIS et al., 2017).

A utilização do protocolo CMF na quimioterapia causa nefrotoxicidade, que pode culminar em disfunção renal. Isso ocorre quando há dificuldade de excreção do quimioterápico e insuficiência renal aguda em alguns pacientes, caso haja precipitação e acúmulo de metabólitos nos túbulos renais (LI et al. 2017a).

Em tumores HER-2 positivos, o fármaco mais utilizado é o trastuzumabe, o qual tem como principal efeito adverso a cardiotoxicidade. Estudos no qual o trastuzumabe foi utilizado em associação ao protocolo CMF indicaram redução do perfil cardiotóxico, sendo esta uma opção de associação para as mulheres cardiopatas que precisam realizar o tratamento com baixo custo (TRYFONIDIS et al. 2017).

Estudos na Ásia demonstraram que mulheres com câncer de mama tratadas com antraciclina obtiveram melhores resultados na taxa de sobrevida livre de doença e sobrevida global, quando comparadas a mulheres tratadas com o uso do protocolo CMF (GHANBARI et al. 2015). Já em mulheres com câncer de mama invasivo residual após a realização de quimioterapia neoadjuvante com associação entre a epirrubicina e o docetaxel, foi realizada a mastectomia, seguida de tratamento adjuvante baseado na utilização do protocolo $\mathrm{CMF}$; não foram 
observados benefícios de redução de carga tumoral com o uso do CMF póscirúrgico para esses tipos tumorais mais agressivos (PROMBERGER et al. 2015).

Em mulheres idosas com câncer de mama, foi feita uma comparação entre o docetaxel e o protocolo CMF como tratamentos adjuvantes. A toxicidade hematológica, mucosite e náusea foram mais frequentes nas mulheres tratadas com CMF. Já as reações de alergia, fadiga, perda capilar, diarreia, dor abdominal, neuropatia, alterações cutâneas e cardiotoxicidade foram observadas nas mulheres tratadas com docetaxel, piorando a qualidade de vida pela maior incidência de reações adversas quando em comparação ao uso do protocolo CMF, que foi mais bem tolerado pelas pacientes (PERRONE et al. 2015).

\section{HORMONIOTERAPIA}

Em função de aumentar a sobrevida e qualidade no tratamento dos pacientes com câncer de mama, novas estratégias terapêuticas são utilizadas, como é o caso da hormonioterapia (TIMMERS et al. 2014). Essa prática consiste em utilizar antagonistas hormonais que sejam semelhantes ou supressores de hormônios, evitando que os estrogênios se liguem aos seus respectivos receptores, impedindo que atuem como fatores de crescimento das células neoplásicas (BRITO et al. 2014).

O tratamento hormonal tem duração longa e apresenta inúmeros efeitos adversos, o que é uma desvantagem em sua utilização. Por outro lado, cerca de $60 \%$ das mulheres com menos de 50 anos e $80 \%$ das mulheres com idade acima de 50 anos apresentam-se positivas para o receptor de estrogênio, fazendo com que a hormonioterapia seja o tratamento de escolha nesses casos (BRITO et al. 2014). As principais drogas utilizadas no tratamento hormonal são o tamoxifeno e os inibidores de aromatase, como o anastrozol (CARVALHO et al., 2015).

\section{TAMOXIFENO}

O tamoxifeno é um medicamento antagonista dos receptores de estrógeno e seu mecanismo de ação se baseia em competir com o estradiol pelo receptor tumoral estrogênico (LAGARES et al., 2013). Em células da linhagem MCF7 cultivadas, o tamoxifeno foi capaz de suprimir a proliferação, migração e invasão das células, produzir espécies reativas de oxigênio e induzir a morte celular das células tumorais por apoptose (LI et al., 2017b).

Além de atuar como antagonista, o tamoxifeno também pode exercer uma ação agonista parcial, o que previne a ocorrência de desmineralização óssea, principalmente nas mulheres em idade pós-menopáusica. Em contrapartida, essa ação agonista tem como consequência o aumento do risco de desenvolvimento de câncer endometrial e tromboembolismo (DEMICHELI; AMBROGI, 2014).

O tamoxifeno é amplamente utilizado e tem constituído um fator importante na redução das taxas de mortalidade por câncer de mama nos últimos anos. A indicação para o tratamento é feita após a avaliação dos receptores hormonais de estrógeno; caso a paciente tenha resultado positivo para os receptores, o uso do tamoxifeno é a terapia de escolha (BARRON et al., 2013).

É um fármaco administrado por via oral, o que faz com que a paciente tenha um importante papel para que haja o sucesso do tratamento (PERRONE et al., 2014). Um comprimido deve ser utilizado diariamente durante um período de ENCICLOPÉDIA BIOSFERA, Centro Científico Conhecer - Goiânia, v.14 n.26; p. 588 
cinco anos, e o uso por períodos inferiores está associado a um aumento significativo na recorrência do tumor e mortalidade da paciente (BRITO et al. 2014).

Possui efeitos adversos como a retenção hídrica, fogachos, alterações do ciclo menstrual e alterações vaginais, como corrimentos e sangramentos. Em alguns casos, pode ocorrer o desenvolvimento de câncer de colo do útero, náuseas e envolvimento do sistema nervoso da paciente, causando mudanças de humor e depressão. Outro relato dos pacientes é a ocorrência de ganho de peso excessivo em decorrência do tratamento com tamoxifeno, e, apesar dos efeitos adversos, continua sendo a melhor opção para a hormonioterapia, principalmente nas mulheres acometidas pelo câncer de mama após o período da menopausa (RUBOVSZKY; HORVÁTH, 2017).

O uso da terapia hormonal com tamoxifeno antes da cirurgia reconstrutiva da mama também parece estar associado a um risco maior de complicações de cicatrização de feridas (BILLON et al. 2017). Além disso, em células endometriais cultivadas in vitro, o tamoxifeno foi responsável pela transcrição de um fator nuclear eritritóide, o Nrf-2, que é considerado um fator oncopromotor, resultando em hiperplasia das células do endométrio, demonstrando o risco do uso desse fármaco nas mulheres (FENG et al. 2017).

\section{INIBIDORES DA AROMATASE}

A aromatase é uma enzima da família dos citocromos. Sua expressão é alta na placenta, células dos folículos ovarianos e tecidos glandulares, como a gordura subcutânea, tecido mamário normal e também tecido mamário tumoral. Os inibidores dessa enzima bloqueiam o processo enzimático adrenal que resulta na síntese de estrógeno, causando supressão hormonal. Eles são classificados, de acordo com seu mecanismo de ação, em tipo 1 e tipo 2. Dentre os inibidores do tipo 1 destaca-se o examestrano, que age por meio de uma ligação irreversível à aromatase que impede a conversão da androstenediona, o que bloqueia a via metabólica de síntese estrogênica. Já os inibidores do tipo 2 são os mais conhecidos e utilizados, a exemplo o anastrozol, que também se liga à aromatase, porém com ação mais específica em comparação aos inibidores do tipo 1 (DOWSETT et al. 2009).

Existe um problema na utilização desses fármacos, principalmente nas mulheres no período que antecede a menopausa, pois promovem aumento na secreção de gonadotrofinas. No entanto, de maneira geral, apresentam menores efeitos adversos em comparação ao tamoxifeno. Existe relato de uma paciente que desenvolveu hepatite autoimune em decorrência do tratamento com anastrozol (KLAPKO et al. 2017), além do tratamento também ter sido associado ao aumento do risco de desenvolvimento de osteoporose (LIPTON et al. 2017) e à indução de lúpus eritematoso cutâneo (FISHER et al. 2016).

Apesar dos efeitos adversos, o uso do anastrozol é considerado atualmente um tratamento de primeira linha de tumores metastáticos e agressivos. Mesmo nos tumores menos agressivos, em estágio inicial, os resultados também são promissores no tratamento adjuvante de mulheres após a menopausa, sendo este um quimioterápico capaz de agir na quimioprevenção do câncer (BARROSOLIVEIRA et al. 2017). 


\section{FULVESTRANTO}

O fulvestranto faz parte de uma nova classe de fármacos para o tratamento endócrino do câncer de mama que apresentam ação antagonista aos receptores de estrógeno, porém com mecanismo que o difere do tamoxifeno e inibidores da aromatase (HU et al. 2017). Esse fármaco é um análogo 7- $\alpha$ alquilsulfinil do $17 \beta$-estradiol que age competindo pelos receptores de estrógeno; porém, ao contrário do tamoxifeno, o fulvestranto não apresenta atividade agonista (MOSCETTI et al. 2017), pois se liga, bloqueia e degrada o receptor estrogênico. Assim como o anastrozol, é indicado para o tratamento de mulheres que desenvolvem câncer de mama num período após a menopausa, e que são positivas aos receptores de estrógeno (BOÉR, 2017).

O fármaco é utilizado geralmente, na dosagem de $250 \mathrm{mg}$ por via intramuscular (LEE et al. 2017). No entanto, quando utilizado na dosagem de $500 \mathrm{mg}$, ocorre uma melhora nos resultados com consequente aumento da taxa de sobrevivência, principalmente quando em comparação aos resultados obtidos com 0 uso do anastrozol (NATHAN et al. 2017).

No uso do fulvestranto durante o tratamento adjuvante do câncer de mama, a dosagem mais alta de $500 \mathrm{mg}$ foi associada a um aumento da atividade biológica, em comparação ao uso da dosagem de $250 \mathrm{mg}$, resultando em melhor redução na expressão de receptores de estrógeno e inibição do crescimento celular (MOSCETTI et al. 2017).

No estudo CONFIRM (Comparison of Faslodex in Recurrent or Metastatic Breast Cancer), o fulvestranto foi utilizado nas dosagens de $250 \mathrm{mg}$ e $500 \mathrm{mg}$. Com o uso da maior dosagem, não foram observadas diferenças substanciais na incidência e severidade de efeitos adversos, sendo que os relatos mais frequentes pelas pacientes incluíram o desenvolvimento de bronquite, dispneia e alterações gastrointestinais como náuseas e vômitos (ROBERTSON et al. 2016; BOÉR, 2017). Essa baixa incidência de efeitos adversos faz com que a busca pelo tratamento com o fulvestranto aumente (MOSCETTI et al. 2017).

A fim de se evitar o desenvolvimento de resistência aos medicamentos e potencializar a ação dos mesmos, são feitas as combinações entre duas ou mais drogas. No caso do fulvestranto, uma das combinações testadas foi com o anastrozol para o tratamento de mulheres positivas aos receptores de estrógeno. Infelizmente, não foram observadas vantagens na associação entre as drogas no tratamento das pacientes com câncer de mama, com melhores resultados na utilização das drogas de formas isoladas (BOÉR, 2017).

Embora não seja um fármaco muito utilizado em associações, o uso do fulvestranto é considerado uma terapia sistêmica segura e efetiva, servindo como opção no tratamento de mulheres com câncer de mama, principalmente no período posterior a menopausa (LEE et al. 2017).

\section{A BUSCA POR NOVAS ALTERNATIVAS DE TRATAMENTO}

A evolução da medicina e da ciência em busca de melhores tratamentos para o câncer de mama atingiu bons resultados, com importante redução na mortalidade e aumento na taxa de sobrevivência. Apesar dos avanços, o câncer de mama continua sendo o tipo de tumor que ocorre com maior frequência em todo o 
mundo, e o de maior ocorrência em mulheres, com uma incidência que só aumenta ao longo do tempo (FOSTER et al. 2017).

Esses dados mostram que existe uma necessidade crescente de desenvolvimento de novas alternativas para o tratamento. Por esse motivo, muitos países desenvolvidos têm alocado vastos recursos econômicos para o desenvolvimento de pesquisas e estratégias terapêuticas que sejam capazes de reduzir as recidivas dos tumores e a taxa de mortalidade (BONILLA et al. 2017).

Ainda é preciso citar que as opções de tratamento hoje disponíveis são caras e de difícil acesso por grande parte da população mundial. Os quimioterápicos e fármacos utilizados também apresentam frequentes efeitos adversos, com taxas de cura variáveis, e não existe um tratamento totalmente efetivo para o câncer de mama (FOSTER et al. 2017).

Dessa forma, em algumas partes do mundo, a busca por medicamentos complementares e terapias alternativas é intensa, o que faz com que as plantas medicinais tenham destaque. Esses vegetais apresentam uma série de propriedades curativas e possuem compostos com ação em diversos tipos de tumores e doenças, com resultados satisfatórios em muitas pesquisas. É importante salientar que cerca de $50 \%$ das drogas produzidas no mundo, incluindo os quimioterápicos, são derivados de produtos naturais, muitos deles extraídos das plantas (CHOENE; MOTADI, 2016), assim como os taxanos (FOSTER et al. 2017).

\section{AVELós}

O avelós é uma planta originária da África, trazida ao Brasil no ano de 1982, que pode ser encontrada nas regiões Norte e Nordeste do país (SILVA, 2011). caracteriza-se como um arbusto de coloração verde, com ramos cilíndricos bem definidos, que podem atingir nove metros de altura. O nome científico é Euphorbia tirucalli e é uma representante da família das Euphorbiaceae (MUNRO et al., 2015).

No interior do seu caule, a avelós possui um líquido claro, de aspecto leitoso, altamente tóxico, corrosivo e causador de lesões cutâneas, edema, prurido, queimaduras e até necrose dos tecidos, quando em contato com a pele. Caso ingerido, pode causar alterações gastrointestinais, como vômitos, diarreia e irritação e hemorragias na mucosa (SILVA, 2011).

O avelós possui propriedade laxativa, antibiótica, antiviral, analgésica fungicida e hepatoprotetora. Estudos com o extrato da $E$. tirucalli ainda demonstraram importante atividade antioxidante, imunomoduladora e citotóxica (GUPTA et al. 2013), com potencial de ação antitumoral, observado na substância euphol. Esta molécula é extraída a partir do látex presente nos caules da avelós e apresenta efeitos citotóxicos dose e tempo dependentes contra um significante número de linhagens celulares, tais como os carcinomas pancreáticos, tumor esofágico de células escamosas e tumores de mama (MUNRO et al. 2015).

Em células de tumor mamário das linhagens MCF-7 e MDA-MB 231 foram feitos tratamentos com diferentes concentrações de extratos da avelós, durante um período de 48 horas. Houve redução na viabilidade celular, apoptose das células tumorais e bloqueio do ciclo celular entre as fases $\mathrm{G0} / \mathrm{G} 1$, além da expressão de genes apoptóticos nas células tratadas com o extrato (CHOENE; MOTADI, 2016). O mesmo ocorreu em células da linhagem T47D de câncer de mama, onde o euphol bloqueou do ciclo celular na fase G1 (MUNRO et al. 2015). 
A E. tirucalli tem sido utilizada desde a antiguidade como forma de tratamento fitoterápico de várias doenças. Atualmente, representa um avanço das pesquisas para a cura do câncer, especialmente o câncer de mama (MUNRO et al., 2015).

\section{$\beta$-LAPACHONA}

A $\beta$-lapachona é um composto derivado das quinonas, obtido a partir do lapachol. É extraído da serragem da madeira das árvores da família Bignoniaceae, conhecidas como ipês (Tabebuia sp.) no Brasil (Figura 1) (FERREIRA et al. 2010; KEE et al. 2016). O lapachol exerce atividade benéfica em várias doenças, e possui propriedades antibacterianas, antioxidantes e antineoplásicas, além de atuarem no tratamento da toxoplasmose, malária e AIDS (JEON et al. 2015).

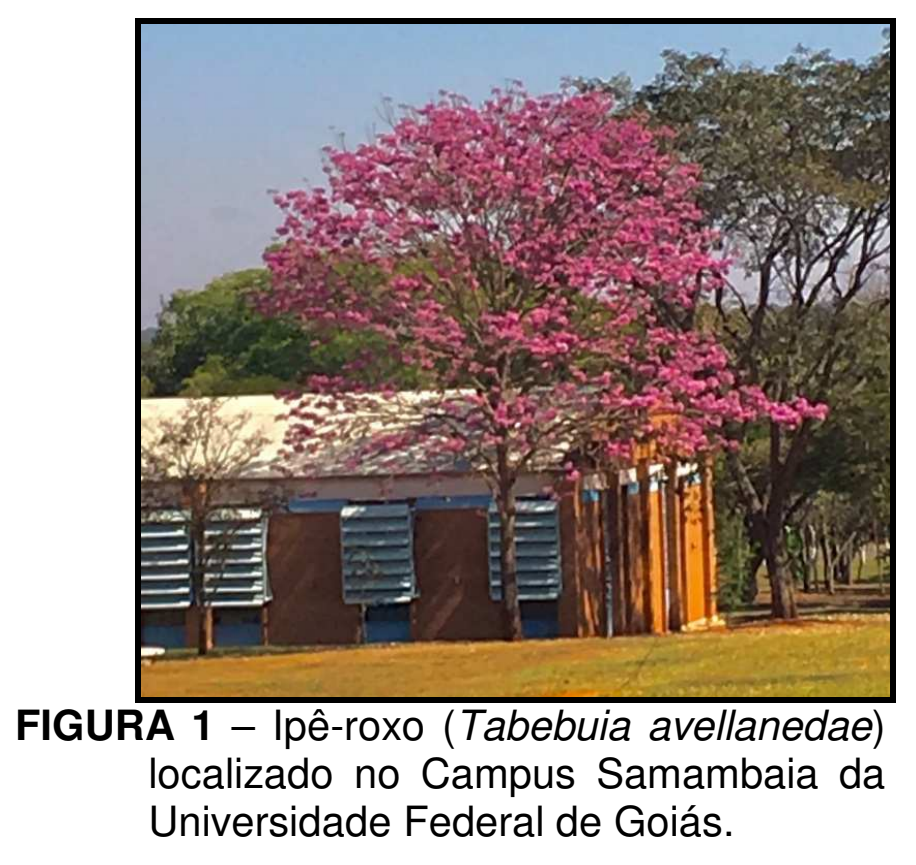

A atuação da $\beta$-lapachona nas células cancerígenas está relacionada à inibição da reparação do DNA. Estimula a produção de espécies reativas de oxigênio, causando estresse oxidativo na célula, com danos irreversíveis a esta, levando a morte celular por apoptose. Além disso, as quinonas atuam nas topoisomerases, enzimas importantes no processo de replicação do DNA, sendo consideradas citotóxicas para as células cancerígenas (FERREIRA et al. 2010).

As quinonas são ubíquas na natureza e conhecidas pelo seu potencial antineoplásico, sendo utilizadas no tratamento de tumores sólidos, com atividade biológica e propriedades estruturais que estão relacionadas a indução de estresse oxidativo e morte das células tumorais (SUNASSEE et al. 2013).

Seu efeito antitumoral já foi demonstrado em diversos tipos de neoplasias, como o tumor de fígado, próstata e cólon. Também é capaz de induzir citotoxicidade em células de melanoma por meio da produção de ROS, induzindo efeitos inibitórios na habilidade metastática do melanoma, suprimindo a metástase pode meio da ativação da via de sinalização MAPK (KEE et al. 2016). Também possui efeito em células de neuroblastoma, causando morte celular por meio da inibição da enzima topoisomerase II, sendo eficaz no tratamento da leucoencefalopatia multifocal 
progressiva (NUKUZUMA et al. 2016). O efeito antimetastático da $\beta$-lapachona também foi investigado em células de câncer colorretal da linhagem CT26, onde o composto foi capaz de induzir apoptose e bloqueio do ciclo celular das células tumorais (KEE et al. 2016).

No câncer de mama, existe uma expressão elevada de uma proteína de ligação à FAD chamada NQO1, capaz de formar homodímeros e reduzir quinonas a hidroquinonas. Essa proteína encontra-se elevada em tumores sólidos, e seu nível de expressão está diretamente relacionado a invasão tumoral, redução na sobrevida livre da doença e sobrevida global. Quando testada em células de câncer de mama, a $\beta$-lapachona exerceu efeito anti-proliferativo e anti-metastático, devido a sua ação sob a expressão da proteína NQO1, o que constitui uma estratégia eficaz para auxiliar no controle da progressão dos tumores de mama positivos para a NQO1 (YANG et al. 2017).

\section{CURCUMINA}

A curcumina é um constituinte do açafrão, um tempero de cor amarela, derivado das raízes da planta Curcuma longa (Figura 4). A cúrcuma é um produto facilmente disponível, barato e com um histórico de ação em diversas doenças. $O$ principal componente da raiz da $C$. longa é um óleo volátil, contendo turmerona, e os agentes que dão cor a cúrcuma são chamados de curcuminóides, sendo que dentre eles se destaca a curcumina (17-bis (4-hidroxi-3-metoxifenil)-1,6-heptadieno-3,5diona) (BANIK et al. 2017).

O açafrão é uma especiaria nativa da Índia, e a curcumina foi isolada pela primeira vez em 1815 dos rizomas da $C$. longa. Desde então, este polifenol foi objeto de estudo de diversos cientistas, apresentando propriedade antioxidante, antiinflamatória, antineoplásica, antiviral, antibacteriana e antifúngica (KUNNUMAKKARA et al. 2017).

Experimentos in vitro desmontraram que a curcumina possui atividade antitumoral promissora testada em tumores de mama, pâncreas, próstata, tumores sólidos e do colo uterino, obtendo excelentes resultados. Com isso, os pesquisadores passaram a se concentrar na melhora da biodisponibilidade do composto, resultando em diferentes formulações para a comercialização da curcumina (ADIWIDJAJA et al. 2017).

O mecanismo de ação da curcumina envolve a regulação transcricional de vários fatores de crescimento, citocinas, proteínas quinases e enzimas, porém o mecanismo pelo qual esse composto age no comportamento tumoral, especialmente na invasão de tumores, ainda não foi completamente elucidado, embora a curcumina tenha ação moduladora nos alvos que são inibidos pelas principais drogas para o tratamento do câncer aprovadas pela FDA (Food and Drug Administration) (KUNNUMAKKARA et al. 2017).

As principais vias de sinalização do composto são a NFKB, que é um complexo proteico que age como fator de transcrição, envolvido na resposta celular; PI3K, que são enzimas envolvidas no crescimento celular, proliferação, diferenciação e sobrevivência das células tumorais; Akt, que age em processos de apoptose, proliferação celular, transcrição e migração e outras, como mTOR, MAPK e JAK/STAT, todas relacionadas a processos celulares de apoptose, proliferação e diferenciação (BANIK et al. 2017).

Em experimentos com células de câncer de bexiga, a curcumina foi capaz de ativar vias de sinalização pró-apoptóticas e anti-tumorigênicas, inibindo a 
sobrevivência e invasão das células tumorais. Outros estudos foram feitos em camundongos com câncer gástrico, que foram submetidos ao tratamento com curcumina, a qual inibiu a proliferação tumoral por meio do desencadeamento da morte celular por apoptose. Além disso, a curcumina também foi responsável pelo aumento do $\mathrm{pH}$ gástrico e redução na secreção de gastrina e ácidos, o que inibe a progressão do câncer gástrico (ZHOU et al. 2017).

Com relação ao câncer de mama, estudos compararam o docetaxel à curcumina, que obteve bons resultados no controle da progressão tumoral. Seu uso foi bem tolerado e causou menos efeitos adversos, sendo a maior parte deles relacionados ao trato gastrointestinal, como refluxo, inchaço e desconforto abdominal (FADUS et al. 2017).

Em células da linhagem MCF-7 de câncer de mama, a curcumina reduziu a viabilidade celular e apresentou efeito citotóxico. Por meio da citometria de fluxo, foi possível observar a indução da apoptose das células (WANG et al. 2017). Já em células da linhagem SkBr3 de câncer de mama, a curcumina foi utilizada em associação ao raloxifeno, um fármaco da classe dos taxanos. A capacidade do raloxifeno de suprimir células tumorais foi incrementada, com consequente aumento do numero de células apoptóticas, o que indica que a associação com a curcumina deve ser explorada e demonstra ser uma terapia segura e eficaz no tratamento do câncer de mama (TAURIN et al. 2016).

Diante disso, a curcumina é um agente antineoplásico natural com resultados promissores. Além de agir na apoptose das células tumorais, a curcumina atua em diferentes etapas da carcinogênese da mama. Possui efeito sobre o ciclo celular, proliferação, apoptose, senescência, disseminação do câncer e angiogênese (FADUS et al. 2017).

\section{APIGENINA}

A apigenina (40,5,7-trihidroxiflavona) é uma flavona encontrada em vários alimentos, tais como a salsa, aipo, tomilho, camomila, cebola e laranjas. É considerado um fitoestrógeno, um composto derivado de plantas com estruturas semelhantes a esteroides. Por suas propriedades "hormonais", são também chamados de "hormônios alimentares" (BAl et al. 2014). O interesse pela pesquisa com esses compostos surgiu a partir da análise de dados epidemiológicos que mostram uma redução na taxa de incidência de tumores e mortalidade por câncer em áreas geográficas onde é alto o consumo de frutas e vegetais ricos em flavonoides, o que sugere que esses alimentos exerçam efeito preventivo contra o câncer (TSENG et al., 2017).

A apigenina possui potentes propriedades antioxidantes, antiinflamatórias e anti-neoplásicas e possui potencial antineoplásico em células de câncer de próstata, onde ela promove a ativação de vias apoptóticas, que levam a morte celular (SHUKLA et al. 2014).

Com relação ao câncer de mama, foram feitos estudos em células MCF-7 tratadas com a apigenina, onde foi observada a inibição do crescimento das células tumorais, morte celular por apoptose e produção de ROS. No mesmo estudo, avaliou-se a ação do composto nas células normais humanas (MCF-10A), sendo que a apigenina apresentou pequenos efeitos citotóxicos nessas células, demonstrando baixa toxicidade (BAl et al. 2014). Já em células de outra linhagem de câncer de mama, MDA-MB-231, a apigenina foi capaz de inibir a proliferação e 
crescimento tumoral por meio da indução de bloqueio no ciclo celular entre as fases G2/M (TSENG et al. 2017).

Essa substância também se destaca entre outros fitoestrógenos, com maior ação anti-neoplásica do que a genisteína, quercetina e naringenina, apresentando máximo efeito antiproliferativo em testes comparativos. Além disso, o uso de apigenina em altas dosagens impediu que houvesse a ativação dos receptores de estrógeno pelo $17 \beta$-estradiol, inibindo o crescimento das células tumorais, sendo importante nos casos de câncer de mama hormônio-dependentes (BAl et al., 2014).

Em células da linhagem BT-474 de câncer de mama, a apigenina induziu a via extrínseca da apoptose dependente de caspases, por meio da inibição da transdução de sinais e ativação do fator de transcrição 3 (STAT3). O mesmo ocorreu em células da linhagem MCF-7 resistentes à quimioterapia com adriamicina, onde 0 STAT3 foi ativado e o crescimento celular foi reduzido, o que resultou na quebra da resistência quimioterápica, demonstrando o potencial desse composto no tratamento do câncer de mama (SEO et al. 2017).

\section{URTIGA}

A urtiga (Urtica dioica), da família Urticaceae, é uma planta comum usada desde a antiguidade como um tradicional remédio para distúrbios urinários, hiperplasia prostática, diabetes mellitus e doenças hepáticas. Suas folhas e sementes são amplamente usadas na medicina popular no tratamento de tumores. É também utilizada no tratamento da aterosclerose e doenças cardiovasculares, e seu extrato possui atividade antioxidante e antiproliferativa (FATTAHI et al. 2013). Possui cerca de 500 subespécies, espalhadas pela América, Índia, Malásia e países de clima tropical. Apresenta acetilcolina, histamina, serotonina, moroidina, leucotrienos e ácido fórmico em sua composição (MOHAMMADI et al. 2016).

A presença de lignanas e compostos fenólicos na urtiga está diretamente relacionada ao seu potencial antioxidante, anti-inflamatório e quimioprotetor. Sua capacidade antiproliferativa foi comprovada in vitro em diversos tipos de tumores (MANSOORI et al. 2017). Nas células MCF-7, a urtiga promoveu aumento da apoptose por meio de fragmentação do DNA e liberação de mediadores apoptóticos, como as caspases 3 e 9, além de apresentar efeito anti-proliferativo, sendo um potencial agente quimioterápico para o câncer de mama (FATTAHI et al. 2013).

Há relatos do uso da planta em associação a quimioterápicos no tratamento de tumores. Em células da linhagem MDA-MB-468, quando usada em associação ao paclitaxel, a urtiga aumentou a sensibilidade celular em comparação ao uso do taxano de forma isolada, além de bloquear o ciclo celular entre as fases G2/M, o que resultou em aumento significativo na destruição das células neoplásicas. Com isso, demonstrou-se que a urtiga, ao inibir o crescimento e migração celular, potencializou a ação do quimioterápico paclitaxel e se constituiu em possível candidata ao tratamento do câncer de mama em associação à esta droga (MOHAMMADI et al. 2016).

Outra ação importante observada em células da linhagem MCF-7 foi a supressão do gene miR-21, em decorrência do tratamento com a urtiga, estando este gene relacionado ao surgimento de metástases, migração e crescimento tumoral, o que faz com que essa planta seja foco de pesquisas em busca de novos 
fármacos e possíveis associações visando melhores resultados no tratamento do câncer de mama (FATTAHI et al. 2013).

\section{SULFORAFANO}

A família Brassicaceae (ou Cruciferae) de vegetais crucíferos, como o brócolis, é uma rica fonte de glucosinolatos, que são metabolizados em isotiocianato. Dentre os isotiocianatos, destaca-se o sulforafano, que é considerado um agente quimiopreventivo com potente capacidade de desencadear múltiplos mecanismos nas células para que haja o controle da carcinogênese. Além disso, possui propriedades anti-inflamatórias, pró-apoptóticas e participa de mecanismos moduladores das histonas (MOKHTARI et al. 2017).

Esses compostos eram originalmente reconhecidos como repelentes e inseticidas e, na década de 1960, provou-se serem potentes antineoplásicos. Eles podem atuar como moduladores de enzimas, inibem a progressão do ciclo celular e induzem estresse oxidativo através da depleção de glutationa e também inibem a tioredoxina, uma enzima importante na redução de ROS e que contribui para a proteção celular. O sulforafano já teve sua ação quimiopreventiva testada no câncer de bexiga, além de melhorar a eficácia da radioterapia e reduzir as chances de recidivas em pacientes com câncer de pâncreas (NAUMANN et al. 2017).

Com relação ao câncer de mama, em células das linhagens MDA-MB-231 e MCF-7, foi realizado um tratamento combinando os efeitos do sulforafano com o tratamento com paclitaxel. Houve maior ativação das vias apoptóticas, quando comparada ao tratamento com paclitaxel sozinho (KIM et al. 2017), o que indica que a associação é mais citotóxica para as células tumorais que o uso isolado do paclitaxel.

\section{PIPERLONGUMINA}

É um produto natural encontrado no fruto da planta Pipper longum, presente na Ásia, que possui atividade antitumoral em vários tipos de tumores. E um alcaloide natural, capaz de inibir in vitro e in vivo o crescimento de sarcomas de bexiga e de mama, melanoma e tumores hepáticos. A piperlongumina inibe a enzima antioxidante glutationa transferase, o que resulta em elevada produção intracelular de ROS e consequente morte celular por apoptose das células tumorais, sem apresentar toxicidade nas células normais (JIN et al. 2017). Sua utilização em baixas dosagens exerce atividade citotóxica e antineoplásica em várias linhagens celulares, incluindo os tumores hematológicos, gastrointestinais, tumores sólidos e do sistema nervoso central (PATEL et al. 2017).

Em células da linhagem MCF-7, a piperlongumina foi capaz de promover a autofagia das células por meio da inibição da via de sinalização Akt/mTOR e produção de ROS por meio da inibição enzimática, o que resultou em morte celular. Por isso, atribui-se a este principio ativo importante papel nas pesquisas para tratamentos alternativos do câncer de mama (MAKHOV et al. 2014). O mesmo ocorreu em células da linhagem SkBr3 (JIN et al. 2017).

Quando utilizada em associação ao docetaxel em células da linhagem MDA-MB-231, a piperlongumina foi capaz de aumentar a biodisponibilidade e citotoxicidade do quimioterápico taxano. Essa ação resultou em ação antitumoral sinérgica, que reduziu a viabilidade celular das células tumorais (PATEL et al. 2017). 
Ainda com relação ao câncer de mama, é importante mencionar os receptores da família HER, considerados alvos terapêuticos e associados a um prognostico ruim no caso das pacientes que se apresentam HER positivas. A piperlongumina é capaz de reduzir a expressão desses receptores por meio de um mecanismo de regulação negativa provocado pela produção de ROS, o que indica o potencial terapêutico desse composto no tratamento do câncer de mama (JIN et al. 2017).

\section{HINOKITIOL}

O hinokitiol é um composto natural isolado da madeira das plantas cupressáceas, cujo exemplo mais conhecido são os ciprestes. Esses vegetais são utilizados para a produção de gomas, fornecimento de madeiras e pelo seu valor ornamental. São usados como agentes antimicrobianos em pastas de dente, cosméticos e alimentos, além de apresentar atividade anti-inflamatórias e antineoplásica (TU et al. 2016).

Em células tumorais, o hinokitiol promove apoptose, em uma via caspase3 dependente, o que resulta em morte celular de células de câncer de mama e câncer colorretal. Sua capacidade de agir na caspase- 9 faz com que haja bloqueio no ciclo celular; ainda, o composto induz dois tipos de morte celular, tanto por apoptose, quanto por autofagia, por meio da ativação da via de sinalização Akt/mTOR, o que reduz o crescimento celular in vitro das células de câncer de mama e câncer colorretal (WANG et al. 2016).

\section{OUTRAS SUBSTÂNCIAS COM IMPORTANTE PAPEL NO TRATAMENTO DO CÂNCER DE MAMA}

Testes in vitro com o honokiol, um composto extraído das plantas com flores conhecidas como magnólias, mostraram que este possui a capacidade de inibir a carcinogênese do câncer de mama. Já a nobiletina, um flavonóide natural encontrado na casca das frutas cítricas como a tangerina, possui atividade angiogênica conhecida e, em células MCF-7, foi capaz de inibir a angiogênese tumoral (WANG et al. 2016).

O elemene, um fármaco natural derivado da cúrcuma, possui atividade antitumoral comprovada em ensaios clínicos e experimentais. Além disso, induz bloqueio do ciclo celular entre as fases G2/M e apoptose por meio da ativação da via de sinalização PI3K/Akt em células de tumor mamário (JIANG et al. 2017).

O juglone, uma naftoquinona, assim como o lapachol, é capaz de sensibilizar as células tumorais e reverter a resistência ao fármaco trastuzumabe nas células da linhagem SkBr3, sendo este fármaco muito utilizado em terapias-alvo para o tratamento do câncer de mama (SAJADIMAJD et al. 2017).

$O$ alcaloide natural licorina encontrado em várias plantas, como a Clivia miniata e a Amaryllis belladonna, entre outras, é altamente venenoso. Porém, como efeito potencialmente benéfico, possui capacidade de inibir o crescimento celular das células MDA-MB-231 de tumor mamário, o que suprime a formação de metástases e promove apoptose e bloqueio das vias de sinalização que estimulam 0 desenvolvimento e proliferação tumoral (YING et al. 2017).

O cratoxy, obtido do extrato da folha da Cratoxy formosum, afeta a viabilidade e migração das células de câncer de mama humano. Em testes na ENCICLOPÉDIA BIOSFERA, Centro Científico Conhecer - Goiânia, v.14 n.26; p. 597 
linhagem celular MCF-7, o cratoxy induziu a formação de ROS, amplificou a atividade da caspase 3 e reduziu o potencial de membrana mitocondrial, o que resultou em apoptose da célula tumoral e morte celular (BURANRAT et al. 2017).

\section{CONSIDERAÇÕES FINAIS}

O adenocarcinoma mamário é um tumor agressivo, e embora possa apresentar bom prognóstico, a demora no diagnóstico faz com que a taxa de mortalidade seja alta. $O$ tratamento baseia-se na remoção cirúrgica do tumor e utilização de fármacos quimioterápicos, hormônios ou terapias-alvo, geralmente com altas dosagens, o que faz com que o paciente, tenha inúmeros efeitos adversos.

Muitos protocolos não apresentam bons resultados no tratamento desses tumores, e os pacientes podem desenvolver resistência aos fármacos utilizados. Isso mostra que é importante que sejam feitas mais pesquisas e experimentos visando novas formas de tratamento e o desenvolvimento de novos agentes antineoplásicos, que promovam maiores efeitos citotóxicos ao tumor, com menores efeitos negativos ao paciente.

O avanço das pesquisas para o desenvolvimento de terapias alternativas à quimioterapia vem aumentando a expectativa de cura dos pacientes, e muitos pesquisadores estão em busca de novos fármacos. Várias dessas novas drogas são provenientes das plantas e frutos, onde existe matéria-prima em abundância para a formulação de vários medicamentos. Diversos desses agentes fitoterápicos induzem citotoxicidade nas células tumorais, com ação comprovada em muitas outras doenças, o que traz bons resultados e menores efeitos adversos aos doentes e desperta cada vez mais o interesse da ciência.

Outro ponto de questionamento dos pesquisadores é o fato de que os quimioterápicos não atuam de forma seletiva, sendo inespecíficos, e agindo tanto nas células neoplásicas, quanto nas células normais do paciente, o que causa efeitos negativos a este. O avanço da biologia molecular é importante para o desenvolvimento de marcadores específicos das células tumorais, em busca da destruição apenas das células cancerígenas.

Ao conhecer os mecanismos de ação desses fármacos e suas formas de atuação, é possível lançar mão de novos protocolos para o tratamento do câncer de mama, além de promover maior incentivo às pesquisas e experimentos e mostrar que existem várias outras possibilidades de tratamento que devem ser testadas, e muitas outras a serem descobertas.

\section{REFERÊNCIAS}

ADIWIDJAJA, J., MCLACHLAN, A. J., BODDY, A. V. Curcumin as a clinicallypromising anti-cancer agent: pharmacokinetics and drug interactions. Expert Opinion on Drug Metabolism \& Toxicology, v. 13, n. 9, p. 953-972, 2017. Disponível em: http://www.tandfonline.com/doi/abs/10.1080/17425255.2017.1360279 >. doi: 10.1080/17425255.2017.1360279.

ALMEIDA, V. L. D., LEITÃO, A., REINA, L. D. C. B., MONTANARI, C. A., DONNICI, C. L., LOPES, M. T. P. Câncer e agentes antineoplásicos ciclo-celular específicos e ciclo-celular não específicos que interagem com o DNA: uma introdução. Química

Nova, v. 28 , n. 1, p. 118-129, 2005. Disponível em: < ENCICLOPÉDIA BIOSFERA, Centro Científico Conhecer - Goiânia, v.14 n.26; p. $598 \quad 2017$ 
http://www.scielo.br/pdf/\%0D/qn/v28n1/23048.pdf >. doi: 10.1590/S010040422005000100021.

BAI, H., JIN, H., YANG, F., ZHU, H., CAI, J. Apigenin induced MCF-7 cell apoptosis-associated reactive oxygen species. Scanning, v. 36, n. 6, p. 622-631, 2014. Disponível em: < http://onlinelibrary.wiley.com/doi/10.1002/sca.21170/full >. doi: 10.1002/sca.21170.

BANIK, U., PARASURAMAN, S., ADHIKARY, A. K., OTHMAN, N. H. Curcumin: the spicy modulator of breast carcinogenesis. Journal of Experimental \& Clinical Cancer Research, v. 36, n. 1, p. 98, 2017. Disponível em: < https://jeccr.biomedcentral.com/articles/10.1186/s13046-017-0566-5 >. doi: 10.1186/s13046-017-0566-5.

BARRON, T. I., CAHIR, C., SHARP, L., BENNETT, K. A nested case-control study of adjuvant hormonal therapy persistence and compliance, and early breast cancer recurrence in women with stage I-III breast cancer. British journal of cancer, v. 109, n. 6, p. 1513, 2013. Disponível em: < https://www.ncbi.nlm.nih.gov/pmc/articles/PMC3777010/ >. doi: 10.1038/bjc.2013.518.

BARROS-OLIVEIRA, M. D. C., COSTA-SILVA, D. R., ANDRADE, D. B. D., BORGES, U. S., TAVARES, C. B., BORGES, R. S. et al. Use of anastrozole in the chemoprevention and treatment of breast cancer: A literature review. Revista da Associação Médica Brasileira, v. 63, n. 4, p. 371-378, 2017. Disponível em: < http://www.scielo.br/scielo.php?pid=S0104-42302017000400371\&script=sci_arttext >. doi: 10.1590/1806-9282.63.04.371

BILLON, R., BOSC, R., BELKACEMI, Y., ASSAF, E., SIDAHMED-MEZI, M., HERSANT, B. et al. Impact of adjuvant anti-estrogen therapies (tamoxifen and aromatase inhibitors) on perioperative outcomes of breast reconstruction. Journal of Plastic, Reconstructive \& Aesthetic Surgery, v. S1748-6815, n. 17, p. 30224-3. 2017.

Disponível em:

http://www.sciencedirect.com/science/article/pii/S1748681517302243 >. doi: 10.1016/j.bjps.2017.05.046.

BOÉR, K. Fulvestrant in advanced breast cancer: evidence to date and place in therapy. Therapeutic advances in medical oncology, v. 9, n. 7, p. 465-479, 2017. Disponível em: < http://journals.sagepub.com/doi/abs/10.1177/1758834017711097 >. doi: 10.1177/1758834017711097.

BONILLA, J. M., TABANERA, M. T., MENDOZA, L. R. El cáncer de mama en el siglo XXI: de la detección precoz a los nuevos tratamientos. Radiología, v. 59, n. 5, p. 368-379, 2017. Disponível em: < http://www.sciencedirect.com/science/article/pii/S0033833817301017 >. doi:10.1016/j.rx.2017.06.003

BRITO, C., CRISÓSTOMO PORTELA, M., TEIXEIRA LEITE DE VASCONCELLOS, $M$. Fatores associados à persistência à terapia hormonal em mulheres com câncer de mama. Revista de Saúde Pública, v. 48, n. 2, 2014. Disponível em: < http://www.redalyc.org/html/672/67237024011/ >. doi: 10.1590/S00348910.2014048004799.

BURANRAT, B., MAIRUAE, N., KONSUE, A. Cratoxy formosum leaf extract inhibits proliferation and migration of human breast cancer MCF-7 cells. Biomedicine \& 
Pharmacotherapy, v. 90, p. 77-84, 2017. Disponível em: < http://www.sciencedirect.com/science/article/pii/S0753332217301749 >. doi: 10.1016/j.biopha.2017.03.032.

CARVALHO, M., CONDÉ, C. S. C. Q., DA COSTA FERREIRA, M., DRUMONT, B., HENRIQUE, V. CÂNCER DE MAMA: TRATAMENTO QUIMIOTERÁPICO E QUIMIOPREVENTIVO. ANAIS V SIMPAC, v. 5, n. 1, p. 277-280, 2015. Disponível em:

https://academico.univicosa.com.br/revista/index.php/RevistaSimpac/article/downloa $\mathrm{d} / 120 / 281>$.

CHOENE, M; MOTADI, L. Validation of the Antiproliferative Effects of Euphorbia tirucalli Extracts in Breast Cancer Cell Lines. Molecular Biology, v. 50, n. 1, p. 98110, 2016. Disponível em: < http://molecbio.ru/?view=article\&id=2239 >. doi: $10.1134 /$ S0026893316010040

CINEGAGliA, N. C., Bersano, P. R. O., BÚFAlO, M. C., SFORCIN, J. M. Cytotoxic action of Brazilian propolis in vitro on canine osteosarcoma cells. Phytotherapy Research, v. 27, n. 9, p. 1277-1281, 2013. Disponível em: < http://onlinelibrary.wiley.com/doi/10.1002/ptr.4861/full >. doi: 10.1002/ptr.4861.

CINTRA, J. R. D., GUERRA, M. R., BUSTAMANTE-TEIXEIRA, M. T. Sobrevida específica de pacientes com câncer de mama não-metastático submetidas à quimioterapia adjuvante. Revista da Associação Médica Brasileira, v. 54, n. 4, p . 339-346, 2008. Disponível em: < https://pdfs.semanticscholar.org/cbbf/081b21443b76ea2bdfc0aedb2c9b943f15cd.pdf >. doi: 10.1590/S0104-42302008000400020.

CURIGLIANO, G., CRISCITIELLO, C. Maximizing the Clinical Benefit of Anthracyclines in Addition to Taxanes in the Adjuvant Treatment of Early Breast Cancer. Journal of Clinical Oncology, v. 35, n. 23, p. 2600-2603, 2017. Disponível em: < http://ascopubs.org/doi/abs/10.1200/JCO.2017.72.5960?journalCode=jco >. doi: 10.1200/JCO.2017.72.5960.

DE CASTRO, S. L.; EMERY, F. S.; DA SILVA JÚNIOR, E. N. Synthesis of quinoidal molecules: strategies towards bioactive compounds with an emphasis on lapachones. European journal of medicinal chemistry, v. 69, p. 678-700, 2013. Disponível em:

http://www.sciencedirect.com/science/article/pii/S0223523413005618?via\%3Dihub >. doi: 10.1016/j.ejmech.2013.07.057.

DE SANCTIS, V., ALFÒ, M., DI ROCCO, A., ANSUINELLI, M., RUSSO, E., OSTI, M. F. et al. Second cancer incidence in primary mediastinal B-cell lymphoma treated with methotrexate with leucovorin rescue, doxorubicin, cyclophosphamide, vincristine, prednisone, and bleomycin regimen with or without rituximab and mediastinal radiotherapy: Results from a monoinstitutional cohort analysis of long-term survivors. Hematological oncology, 2017. Disponível em: < http://onlinelibrary.wiley.com/doi/10.1002/hon.2377/full >. doi: 10.1002/hon.2377.

DEMICHELI, R., AMBROGI, F. Comparative benefit from small tumour size and adjuvant chemotherapy: clues for explaining breast cancer mortality decline. BMC cancer, v. 14, n. 1, p. 702, 2014. Disponível em: < https://bmccancer.biomedcentral.com/articles/10.1186/1471-2407-14-702 >. doi: 10.1186/1471-2407-14-702. 
DOWSETT, M., CUZICK, J., INGLE, J., COATES, A., FORBES, J., BLISS, J. et al. Meta-analysis of breast cancer outcomes in adjuvant trials of aromatase inhibitors versus tamoxifen. Journal of Clinical Oncology, v. 28, n. 3, p. 509-518, 2009. Disponível em: < http://ascopubs.org/doi/full/10.1200/JCO.2009.23.1274 >. doi: 10.1200/JCO.2009.23.1274.

FADUS, M. C., LAU, C., BIKHCHANDANI, J., LYNCH, H. T. Curcumin: An age-old anti-inflammatory and anti-neoplastic agent. Journal of traditional and complementary medicine, v. 7, n. 3, p. 339-346, 2017. Disponível em: < http://www.sciencedirect.com/science/article/pii/S2225411016302528 >. doi: 10.1016/j.jtcme.2016.08.002.

FATTAHI, S., ARDEKANI, A. M., ZABIHI, E., ABEDIAN, Z., MOSTAFAZADEH, A., POURBAGHER, R. et al. Antioxidant and apoptotic effects of an aqueous extract of Urtica dioica on the MCF-7 human breast cancer cell line. Asian Pacific Journal of Cancer Prevention, v. 14, n. 9, p. 5317-5323, 2013. Disponível em: < http://www.koreascience.or.kr/article/ArticleFullRecord.jsp?cn=POCPA9_2013_v14n 9_5317 >. doi: 10.7314/APJCP.2013.14.9.5317.

FENG, L., LI, J., YANG, L., ZHU, L., HUANG, X., ZHANG, S. et al. Tamoxifen activates Nrf2-dependent SQSTM1 transcription to promote endometrial hyperplasia. Theranostics, v. 7, n. 7, p. 1890, 2017. Disponível em: < https://www.ncbi.nlm.nih.gov/pmc/articles/PMC5479276/ >. doi: 10.7150/thno.19135.

FERREIRA, S. B., GONZAGA, D. T. G., SANTOS, W. C., ARAÚJO, K. G. L., FERREIRA, V. F. beta-Lapachona: Sua importância em química medicinal e modificações estruturais. Revista Virtual de Química, v. 2, n. 2, p. 140-160, 2010. Disponível em:

https://www.researchgate.net/profile/Daniel_Gonzaga4/publication/277160708_Lapa chona_Sua_importancia_em_quimica_medicinal_e_modificacoes_estruturais/links $/ 5$ 59fbe $1 \mathrm{ff} 08 \mathrm{ae} 3 \mathrm{dbcbe} 86 \mathrm{ed}$ 74/Lapachona-Sua-importancia-em-quimica-medicinal-emodificacoes-estruturais.pdf >. doi: 10.5935/1984-6835.20100013

FISHER, J., PATEL, M., MILLER, M., BURRIS, K. Anastrozole-induced subacute cutaneous lupus erythematosus. Cutis, v. 98, n. 2, p. E22-6, 2016. Disponível em: < http://europepmc.org/abstract/med/27622265 >.

FOSTER, K., YOUNGER, N., AIKEN, W., BRADY-WEST, D., DELGODA, R. Reliance on medicinal plant therapy among cancer patients in Jamaica. Cancer Causes \& Control, p. 1-8, 2017. Disponível em: < https://link.springer.com/article/10.1007/s10552-017-0924-9 >. doi: 10.1007/s10552017-0924-9.

GHANBARI, S., AYATOLLAHI, S. M., ZARE, N. Comparing Role of Two Chemotherapy Regimens, CMF and Anthracycline-Based, on Breast Cancer Survival in the Eastern Mediterranean Region and Asia by Multivariate Mixed Effects Models: a Meta-Analysis. Asian Pacific Journal of Cancer Prevention, v. 16, n. 14, p. 5655-5661, 2015. Disponível em: < http://europepmc.org/abstract/med/26320431 >. doi: 10.7314/APJCP.2015.16.14.5655.

GUPTA, N., VISHNOI, G., WAL, A., WAL, P. Medicinal value of Euphorbia tirucalli. Systematic Reviews in Pharmacy, v. 4, n. 1, p. 40, 2013. Disponível em: < https://search.proquest.com/openview/c0d2e73df6921dd1dad4c10f110f4844/1 ?pqorigsite $=$ gscholar $\& \mathrm{cbl}=226456>$. 
HU, X.; HUANG, W.; FAN, M. Emerging therapies for breast cancer. Journal of hematology \& oncology, v. 10, n. 1, p. 98, 2017. Disponível em: < https://www.ncbi.nlm.nih.gov/pmc/articles/PMC5410098/ > . doi: 10.1186/s13045-0170466-3

JAIN, A., SHARMA, G., KUSHWAH, V., GARG, N. K., KESHARWANI, P., GHOSHAL, G. et al. Methotrexate and beta-carotene loaded-lipid polymer hybrid nanoparticles: a preclinical study for breast câncer. Nanomedicine (Lond), v. 12, n. 15, p. 1851-1872, 2017. Disponível em: < https://www.futuremedicine.com/doi/abs/10.2217/nnm-2017-0011?journalCode=nnm >. doi: 10.2217/nnm-2017-0011.

JEON, Y. J., BANG, W., CHOI, Y. H., SHIM, J. H., CHAE, J. I. Beta-lapachone suppresses non-small cell lung cancer proliferation through the regulation of specificity protein 1. Biological and Pharmaceutical Bulletin, v. 38, n. 9, p. 13021308, 2015. Disponível em: < https://www.jstage.jst.go.jp/article/bpb/38/9/38_b1500159/_article >. doi: 10.1248/bpb.b15-00159.

JIANG, Z., JACOB, J. A., LOGANATHACHETTI, D. S., NAINANGU, P., \& CHEN, B. $\beta$-elemene: Mechanistic studies on cancer cell interaction and its chemosensitization effect. Frontiers in Pharmacology, v. 8, 2017. Disponível em: < https://www.ncbi.nlm.nih.gov/pmc/articles/PMC5343065/ >. doi: 10.3389/fphar.2017.00105.

JIN, H. O., PARK, J. A., KIM, H. A., CHANG, Y. H., HONG, Y. J., PARK, I. C.et al. Piperlongumine downregulates the expression of HER family in breast cancer cells. Biochemical and Biophysical Research Communications, v. 486, n. 4, p. 10831089, 2017. Disponível em: < http://www.sciencedirect.com/science/article/pii/S0006291X17306538 >. doi: 10.1016/j.bbrc.2017.03.166.

JOSHI, M., KUMAR, P., KUMAR, R., SHARMA, G., SINGH, B., KATARE, O. P., et al. Aminated carbon-based "cargo vehicles" for improved delivery of methotrexate to breast cancer cells. Materials Science and Engineering: C, v. 75, p. 1376-1388, $2017 . \quad$ Disponível em: http://www.sciencedirect.com/science/article/pii/S0928493116310475 >. doi: 10.1016/j.msec.2017.03.057.

KEE, J. Y., HAN, Y. H., PARK, J., KIM, D. S., MUN, J. G., AHN, K. S. et al. $\beta-$ Lapachone Inhibits Lung Metastasis of Colorectal Cancer by Inducing Apoptosis of CT26 Cells. Integrative cancer therapies, p. 1534735416681638, 2016. Disponível em: < http://journals.sagepub.com/doi/abs/10.1177/1534735416681638 >. doi: 10.1177/1534735416681638.

KIM, S. H., PARK, H. J., MOON, D. O. Sulforaphane sensitizes human breast cancer cells to paclitaxel-induced apoptosis by downregulating the NF-KB signaling pathway. Oncology Letters, v. 13, n. 6, p. 4427-4432, 2017. https://www.spandidospublications.com/10.3892/ol.2017.5950 10.3892/ol.2017.5950.

KLAPKO, O., GHOULAM, E., JAKATE, S., ESWARAN, S., USHA, L. Anastrozoleinduced Autoimmune Hepatitis: A Rare Complication of Breast Cancer Therapy. Anticancer Research, v. 37, n. 8, p. 4173-4176, 2017. Disponível em: < http://ar.iiarjournals.org/content/37/8/4173.short >. 
KUNNUMAKKARA, A. B., BORDOLOI, D., HARSHA, C., BANIK, K., GUPTA, S. C., AGGARWAL, B. B. Curcumin mediates anticancer effects by modulating multiple cell signaling pathways. Clinical Science, v. 131, n. 15, p. 1781-1799, 2017. Disponível em: < http://www.clinsci.org/content/131/15/1781 >. doi: 10.1042/CS20160935.

LAGARES, É. B., SANTOS, K. D. F., MENDES, R. C., MOREIRA, F. A., ANASTÁCIO, L. R. Excesso de peso em mulheres com diagnóstico de câncer de mama em hormonioterapia com tamoxifeno. Revista brasileira de cancerologia, $\mathrm{v}$. 59, n. 2, p. 201-210, 2013. Disponível em: < http://bases.bireme.br/cgibin/wxislind.exe/iah/online/?IsisScript=iah/iah. $x i s \& s r c=g o o g l e \& b a s e=L I L A C S \& l a n g=p$ \&nextAction=Ink\&exprSearch=723693\&indexSearch=ID >.

LEE, C. I; GOODWIN, A; WILCKEN, N. Fulvestrant for hormone-sensitive metastatic breast cancer. The Cochrane Library, 2017. Disponível em: < http://onlinelibrary.wiley.com/doi/10.1002/14651858.CD011093.pub2/full >. doi: 10.1002/14651858.CD011093.pub2

LI, S., LIU, J., VIRNIG, B. A., COLLINS, A. J. Association between adjuvant chemotherapy and risk of acute kidney injury in elderly women diagnosed with earlystage breast cancer. Breast cancer research and treatment, v. 161, n. 3, p. 515524, 2017a. Disponível em: < https://link.springer.com/article/10.1007/s10549-0164074-7 >. doi: 10.1007/s10549-016-4074-7.

LI, W., SHI, X., XU, Y., WAN, J., WEI, S., ZHU, R. Tamoxifen promotes apoptosis and inhibits invasion in estrogen-positive breast cancer MCF-7 cells. Molecular medicine reports, v. 16, n. 1, p.478-484, 2017b. Disponível em: < https://www.spandidos-publications.com/10.3892/mmr.2017.6603 >. doi: 10.3892/mmr.2017.6603.

LIPTON, A., CHAPMAN, J. A. W., LEITZEL, K., GARG, A., PRITCHARD, K. I., INGLE, J. N. et al. Osteoporosis therapy and outcomes for postmenopausal patients with hormone receptor-positive breast cancer: NCIC CTG MA. 27. Cancer, v. 123, n. 13, p. 2444-2451, 2017. Disponível em: < http://onlinelibrary.wiley.com/doi/10.1002/cncr.30682/full >. doi: 10.1002/cncr.30682.

MAKHOV, P., GOLOVINE, K., TEPER, E., KUTIKOV, A., MEHRAZIN, R., CORCORAN, A. et al. Piperlongumine promotes autophagy via inhibition of Akt/mTOR signalling and mediates cancer cell death. British journal of cancer, v. 110, n. 4, p. 899-907, 2014. Disponível em: < https://www.ncbi.nlm.nih.gov/pmc/articles/PMC3929888/ >. doi: 10.1038/bjc.2013.810.

MANSOORI, B., MOHAMMADI, A., HASHEMZADEH, S., SHIRJANG, S., BARADARAN, A., ASADI, M. et al. Urtica dioica extract suppresses miR-21 and metastasis-related genes in breast cancer. Biomedicine \& Pharmacotherapy, v. 93, p. 95-102, 2017. Disponível em: http://www.sciencedirect.com/science/article/pii/S0753332217307308 >. doi: 10.1016/j.biopha.2017.06.021.

MOHAMMADI, A., MANSOORI, B., AGHAPOUR, M., SHIRJANG, S., NAMI, S., BARADARAN, B. The Urtica dioica extract enhances sensitivity of paclitaxel drug to MDA-MB-468 breast cancer cells. Biomedicine \& Pharmacotherapy, v. 83, p. 835842, 2016. Disponível em: < http://www.sciencedirect.com/science/article/pii/S075333221630840X >. doi: 10.1016/j.biopha.2016.07.056. 
MOKHTARI, R. B., BALUCH, N., HOMAYOUNI, T. S., MORGATSKAYA, E., KUMAR, S., KAZEMI, P. et al. The role of Sulforaphane in cancer chemoprevention and health benefits: a mini-review. Journal of cell communication and signaling, p. 1-11, 2017. Disponível em: < https://link.springer.com/article/10.1007/s12079-0170401-y >. doi: 10.1007/s12079-017-0401-y.

MOLAVI, O., NARIMANI, F., ASIAEE, F., SHARIFI, S., TARHRIZ, V., SHAYANFAR, A. et al. Silibinin sensitizes chemo-resistant breast cancer cells to chemotherapy. Pharmaceutical biology, v. 55, n. 1, p. 729-739, 2017. Disponível em: < http://www.tandfonline.com/doi/full/10.1080/13880209.2016.1270972 >.doi: 10.1080/13880209.2016.1270972.

MONTEIRO, D. L. M., TRAJANO, A. J. B., MENEZES, D. C. S., SILVEIRA, N. L. M., MAGALHÃES, A. C., DE MIRANDA, F. R. D. et al. Câncer de mama na gravidez e quimioterapia: revisão sistemática. Revista da Associação Médica Brasileira, v. 59, n. 2, p. 174-180, 2013. Disponível em: < http://www.sciencedirect.com/science/article/pii/S0104423013000067 >. doi: 10.1016/j.ramb.2012.10.003.

MOSCETTI, L., FABBRI, M. A., NATOLI, C., VICI, P., GAMUCCI, T., SPERDUTI, I., et al. Fulvestrant 500 milligrams as endocrine therapy for endocrine sensitive advanced breast cancer patients in the real world: the Ful500 prospective observational trial. Oncotarget, v. 8, n. 33, p. 54528-54536, 2017. Disponível em: < https://www.ncbi.nlm.nih.gov/pmc/articles/PMC5589600/ >. doi: 10.18632/oncotarget.17262.

MUNRO, B., VUONG, Q. V., CHALMERS, A. C., GOLDSMITH, C. D., BOWYER, M. C., SCARLETT, C. J. Phytochemical, antioxidant and anti-cancer properties of Euphorbia tirucalli methanolic and aqueous extracts. Antioxidants, v. 4, n. 4, p. 647661, 2015. Disponível em: < http://www.mdpi.com/2076-3921/4/4/647/htm >. doi: 10.3390/antiox4040647.

NATHAN, Mark R.; SCHMID, Peter. A Review of Fulvestrant in Breast Cancer. Oncology and Therapy, v. 5, n. 1, p. 17-29, 2017. Disponível em: < https://www.ncbi.nlm.nih.gov/pmc/articles/PMC5488136/ > . doi: 10.1007/s40487-0170046-2.

NAUMANN, P., LIERMANN, J., FORTUNATO, F., SCHMID, T. E., WEBER, K. J., DEBUS, J. et al. Sulforaphane enhances irradiation effects in terms of perturbed cell cycle progression and increased DNA damage in pancreatic cancer cells. PloS one, v. 12, n. 7 , p. e0180940, 2017. Disponível em: < http://journals. . los.org/plosone/article?id=10.1371/journal.pone.0180940 >. doi: 10.1371/journal.pone.0180940.

NUKUZUMA, S., NAKAMICHI, K., KAMEOKA, M., SUGIURA, S., NUKUZUMA, C., TASAKI, T. et al. Suppressive effect of topoisomerase inhibitors on JC polyomavirus propagation in human neuroblastoma cells. Microbiology and immunology, v. 60, n. $4, \quad$ p. 253-260, 2016. Disponível em: < http://onlinelibrary.wiley.com/doi/10.1111/1348-0421.12372/full >. doi: 10.1111/13480421.12372.

OKINO SAWADA, N., NICOLUSSI, A. C., OKINO, L., COELHO CARDOZO, F. M., FONTÃO ZAGO, M. M. Avaliação da qualidade de vida de pacientes com câncer submetidos à quimioterapia. Revista da Escola de Enfermagem da USP, v. 43, n. 
3, 2009. Disponível em: < http://www.redalyc.org/html/3610/361033299012/>. http://dx.doi.org/10.1590/S0080-62342009000300012.

PATEL, K., CHOWDHURY, N., DODDAPANENI, R., BOAKYE, C. H., GODUGU, C., SINGH, M. Piperlongumine for Enhancing Oral Bioavailability and Cytotoxicity of Docetaxel in Triple-Negative Breast Cancer. Journal of pharmaceutical sciences, v. $104, \quad$ n. $12, \quad$ p. 4417-4426, 2015. Disponível em: < http://onlinelibrary.wiley.com/doi/10.1002/jps.24637/full >. doi: 10.1002/jps.24637.

PERRONE, F., NUZZO, F., DI RELLA, F., GRAVINA, A., IODICE, G., LABONIA, V. et al. Weekly docetaxel versus CMF as adjuvant chemotherapy for older women with early breast cancer: final results of the randomized phase III ELDA trial. Annals of Oncology, v. 26, n. 4, p. 675-682, 2015. Disponível em: < https://academic.oup.com/annonc/article/26/4/675/203802/Weekly-docetaxel-versusCMF-as-adjuvant $>$. doi: 10.1093/annonc/mdu564.

PROMBERGER, R., DUBSKY, P., MITTLBÖCK, M., OTT, J., SINGER, C., SEEMANN, R. et al. Postoperative CMF Does Not Ameliorate Poor Outcomes in Women With Residual Invasive Breast Cancer After Neoadjuvant Epirubicin/Docetaxel Chemotherapy. Clinical breast cancer, v. 15, n. 6, p. 505-511, $2015 . \quad$ Disponível em:

http://www.sciencedirect.com/science/article/pii/S1526820915001238 >. doi: 10.1016/j.clbc.2015.06.007.

ROBERTSON, J. F., BONDARENKO, I. M., TRISHKINA, E., DVORKIN, M., PANASCI, L., MANIKHAS, A. et al. Fulvestrant $500 \mathrm{mg}$ versus anastrozole $1 \mathrm{mg}$ for hormone receptor-positive advanced breast cancer (FALCON): an international, randomised, double-blind, phase 3 trial. The Lancet, v. 388, n. 10063, p. 2997-3005, 2016. Disponível em:

http://www.sciencedirect.com/science/article/pii/S0140673616323893 >. doi: 10.1016/S0140-6736(16)32389-3.

RUBOVSZKY, G; HORVÁTH, Z. Recent Advances in the Neoadjuvant Treatment of Breast Cancer. Journal of breast cancer, v. 20, n. 2, p. 119-131, 2017. Disponível em:

https://www.synapse.koreamed.org/search.php?where=aview\&id=10.4048/jbc.2017.

20.2.119\&code=0096JBC\&vmode=FULL $>$. doi: 10.4048/jbc.2017.20.2.119.

SABZICHI, M., MOHAMMADIAN, J., MOHAMMADI, M., JAHANFAR, F., MOVASSAGH POUR, A. A., HAMISHEHKAR, H., et al. Vitamin D-Loaded Nanostructured Lipid Carrier (NLC): A New Strategy for Enhancing Efficacy of Doxorubicin in Breast Cancer Treatment. Nutrition and Cancer, p. 1-9, 2017. Disponível em:

http://www.tandfonline.com/doi/abs/10.1080/01635581.2017.1339820 >. doi: 10.1080/01635581.2017.1339820.

SAJADIMAJD, S., YAZDANPARAST, R. Sensitizing effect of juglone is mediated by down regulation of Notch1 signaling pathway in trastuzumab-resistant SKBR3 cells. Apoptosis, v. 22, n. 1, p. 135-144, 2017. Disponível em: < https://link.springer.com/article/10.1007/s10495-016-1291-9 >. doi: 10.1007/s10495016-1291-9

SEO, H. S., KU, J. M., CHOI, H. S., WOO, J. K., LEE, B. H., KIM, D. S. et al. Apigenin overcomes drug resistance by blocking the signal transducer and activator of transcription 3 signaling in breast cancer cells. Oncology Reports, v. 38, n. 2, p. ENCICLOPÉDIA BIOSFERA, Centro Científico Conhecer - Goiânia, v. 14 n.26; p. 605 
715-724, 2017. Disponível em: < https://www.spandidospublications.com/or/38/2/715?text=fulltext >. doi: 10.3892/or.2017.5752.

SHAFIEI-IRANNEJAD, V., SAMADI, N., YOUSEFI, B., SALEHI, R., VELAEI, K., ZARGHAMI, N. Metformin enhances doxorubicin sensitivity via inhibition of doxorubicin efflux in P-gp-overexpressing MCF-7 cells. Chemical biology \& drug design, 2017. Disponível em: < http://onlinelibrary.wiley.com/doi/10.1111/cbdd.13078/full >. doi: 10.1111/cbdd.13078.

SHUKLA, S., FU, P., GUPTA, S. Sanjay. Apigenin induces apoptosis by targeting inhibitor of apoptosis proteins and Ku70-Bax interaction in prostate cancer. Apoptosis, v. 19, n. 5, p. 883-894, 2014. Disponível em: < https://link.springer.com/article/10.1007/s10495-014-0971-6 >. doi: 10.1007/s10495014-0971-6.

SILVA, Pamella Araújo; RIUL, Sueli da Silva. Câncer de mama: fatores de risco e detecção precoce. Revista Brasileira de Enfermagem, v. 64, n. 6, p. 1016-21, 2011.

Disponível em: < http://www.scielo.br/scielo.php?script=sci_arttext\&pid=S0034$71672011000600005 \&$ lng $=$ pt\&tlng=pt.

http://dx.doi.org/10.1590/S0034-

71672011000600005

SOUCHEK, J. J., DAVIS, A. L., HILL, T. K., HOLMES, M. B., QI, B., SINGH, P. K. et al. Combination treatment with orlistat-containing nanoparticles and taxanes is synergistic and enhances microtubule stability in taxane-resistant prostate cancer cells. Molecular Cancer Therapeutics, v. 16, n. 9, p.1819-1830, 2017. Disponível em: < http://mct.aacrjournals.org/content/early/2017/06/14/1535-7163.MCT-17-0013 >. doi: 10.1158/1535-7163.MCT-17-0013.

SOUZA CD, FELFILI JM. Uso de plantas medicinais na região de Alto Paraíso de Goiás, GO, Brasil. Acta Botânica Brasileira, v. 20, n. 1, p. 135-142, 2006. Disponível em: < http://www.scielo.br/scielo.php?script=sci_arttext\&pid=S0102$33062006000100013 \&$ lang=pt $>$. doi: $0.1590 /$ S0102-33062006000100013.

SUNASSEE, S. N., VEALE, C. G., SHUNMOOGAM-GOUNDEN, N., OSONIYI, O., HENDRICKS, D. T., CAIRA, M. R. et al. Cytotoxicity of lapachol, $\beta$-lapachone and related synthetic 1, 4-naphthoquinones against oesophageal cancer cells. European journal of medicinal chemistry, v. 62, p. 98-110, 2013. Disponível em: < http://www.sciencedirect.com/science/article/pii/S0223523413000044 >. doi: 10.1016/j.ejmech.2012.12.048.

TAURIN, S., NIMICK, M., LARSEN, L., ROSENGREN, R. J. A novel curcumin derivative increases the cytotoxicity of raloxifene in estrogen receptor-negative breast cancer cell lines. International journal of oncology, v. 48, n. 1, p. 385-398, 2016. https://www.spandidos-publications.com/ijo/48/1/385 10.3892/ijo.2015.3252.

TAVANGAR, F., SEPEHRI, H., JAZI, M. S., ASADI, J. Amphotericin B potentiates the anticancer activity of doxorubicin on the MCF-7 breast cancer cells. Journal of Chemical Biology, v. 10, n. 3, p. 143-150, 2017. Disponível em: < https://link.springer.com/article/10.1007/s12154-017-0172-1 >. doi: 10.1007/s12154017-0172-1. 
TIMMERS, L., BOONS, C. C., KROPFF, F., VAN DE VEN, P. M., SWART, E. L., SMIT, E. F. et al. Adherence and patients' experiences with the use of oral anticancer agents. Acta Oncologica, v. 53, n. 2, p. 259-267, 2014. Disponível em: < http://www.tandfonline.com/doi/abs/10.3109/0284186X.2013.844353 >. doi: 10.3109/0284186X.2013.844353

TRYFONIDIS, K., MARREAUD, S., KHALED, H., DE VALK, B., VERMORKEN, J., WELNICKA-JASKIEWICZ, M. et al. Cardiac safety, efficacy, and correlation of serial serum HER2-extracellular domain shed antigen measurement with the outcome of the combined trastuzumab plus CMF in women with HER2-positive metastatic breast cancer: results from the EORTC 10995 phase II study. Breast Cancer Research and Treatment, v. 163, n. 3, p. 507-515, 2017. Disponível em: < https://link.springer.com/article/10.1007/s10549-017-4203-y >. doi: 10.1007/s10549017-4203-y.

TSENG, T. H., CHIEN, M. H., LIN, W. L., WEN, Y. C., CHOW, J. M., CHEN, C. K. et al. Inhibition of MDA-MB-231 breast cancer cell proliferation and tumor growth by apigenin through induction of $\mathrm{G} 2 / \mathrm{M}$ arrest and histone $\mathrm{H} 3$ acetylation-mediated p21WAF1/CIP1 expression. Environmental toxicology, v. 32, n. 2, p. 434-444, 2017. Disponível em: < http://onlinelibrary.wiley.com/doi/10.1002/tox.22247/full >. doi: $10.1002 /$ tox.22247.

TU, D. G., YU, Y., LEE, C. H., KUO, Y. L., LU, Y. C., TU, C. W. et al. Hinokitiol inhibits vasculogenic mimicry activity of breast cancer stem/progenitor cells through proteasome-mediated degradation of epidermal growth factor receptor. Oncology letters, v. 11, n. 4, p. 2934-2940, 2016. Disponível em: < https://www.spandidospublications.com/ol/11/4/2934?text=fulltext >. doi: 10.3892/ol.2016.4300.

VIEIRA, D. S. C., DUFLOTH, R. M., SCHMITT, F. C. L., ZEFERINO, L. C. Breast cancer: new concepts in classification. Revista Brasileira de Ginecologia e Obstetrícia, v. 30, n. 1, p. 42-47, 2008. Disponível em: < http://www.scielo.br/scielo.php?pid=S0100-

$72032008000100008 \&$ script=sci_arttext\&tlng=pt $\quad$ >. doi: $10.1590 /$ S010072032008000100008.

WANG, W. K., LIN, S. T., CHANG, W. W., LIU, L. W., LI, T. Y. T., KUO, C. Y., et al. Hinokitiol induces autophagy in murine breast and colorectal cancer cells. Environmental toxicology, v. 31, n. 1, p. 77-84, 2016. Disponível em: < http://onlinelibrary.wiley.com/doi/10.1002/tox.22023/full >. doi: 10.1002/tox.22023.

WANG, X., HANG, Y., LIU, J., HOU, Y., WANG, N., WANG, M. Anticancer effect of curcumin inhibits cell growth through miR-21/PTEN/Akt pathway in breast cancer cell. Oncology Letters, v. 13, n. 6, p. 4825-4831, 2017. Disponível em: < https://www.spandidos-publications.com/ol/13/6/4825?text=abstract $\quad>$. doi: 10.3892/ol.2017.6053.

WU, C. W., LIU, H. C., YU, Y. L., HUNG, Y. T., WEI, C. W., YIANG, G. T. Combined treatment with vitamin $\mathrm{C}$ and methotrexate inhibits triple-negative breast cancer cell growth by increasing $\mathrm{H} 2 \mathrm{O} 2$ accumulation and activating caspase-3 and p38 pathways. Oncology Reports, v. 37, n. 4, p. 2177-2184, 1899. Disponível em: < https://www.spandidos-publications.com/or/37/4/2177?text=fulltext $\quad>$. doi: 10.3892/or.2017.5439. 
YANG, Y., ZHOU, X., XU, M., PIAO, J., ZHANG, Y., LIN, Z. et al. $\beta$-lapachone suppresses tumour progression by inhibiting epithelial-to-mesenchymal transition in NQO1-positive breast cancers. Scientific Reports, v. 7, 2017. Disponível em: < https://www.ncbi.nlm.nih.gov/pmc/articles/PMC5457413/ >. doi: 10.1038/s41598-01702937-0.

YING, X., HUANG, A., XING, Y., LAN, L., YI, Z., HE, P. Lycorine inhibits breast cancer growth and metastasis via inducing apoptosis and blocking Src/FAK-involved pathway. Science China Life Sciences, v. 60, n. 4, p. 417-428, 2017. Disponível em: < https://link.springer.com/article/10.1007/s11427-016-0368-y >. doi: 10.1007/s11427-016-0368-y.

ZHANG, Y., SONG, L., CAI, L., WEI, R., HU, H., JIN, W. Effects of baicalein on apoptosis, cell cycle arrest, migration and invasion of osteosarcoma cells. Food and chemical toxicology, v. 53, p. 325-333, 2013. Disponível em: < http://www.sciencedirect.com/science/article/pii/S0278691512008927 >. doi: 10.1016/j.fct.2012.12.019.

ZHOU, S, YAO, D, GUO, L, TENG, L. Curcumin suppresses gastric cancer by inhibiting gastrin-mediated acid secretion. FEBS Open Bio Journal, v. 7, n. 8, p. 1078-1084, 2017. Disponível em: < http://onlinelibrary.wiley.com/doi/10.1002/22115463.12237/full >. doi: 10.1002/2211-5463.12237. 